\title{
Photodynamic DNA damage induced by phycocyanin and its repair in Saccharomyces cerevisiae
}

M. Pádula1,2 and S. Boiteux ${ }^{1}$
'Laboratoire de Radiobiologie de l'ADN, Commissariat à l'Energie Atomique, Département de Radiobiologie et Radiopathologie, UM R217 Centre National de la Recherche Scientifique, BP6, Fontenay-aux-Roses, France ²Departamento de Fármacos, Faculdade de Farmácia, Universidade Federal do Rio de Janeiro, Rio de Janeiro, RJ, Brasil

\section{Correspondence}

M. Pádula

Departamento de Fármacos

Faculdade de Farmácia, UFRJ

CCS, Bloco B sub-solo (S 219)

21941-590 Rio de Janeiro, RJ

Brasil

E-mail: depadula@openlink.com.br

Research supported by the

Commissariat à l'Energie Atomique (CEA), the Centre National de la

Recherche Scientifique (CNRS) and CNPq.

Received January 20, 1999

Accepted June 22, 1999

\section{Abstract}

In the present study, we analyzed DNA damage induced by phycocyanin (PHY) in the presence of visible light (VL) using a set of repair endonucleases purified from Escherichia coli. We demonstrated that the profile of DNA damage induced by PHY is clearly different from that induced by molecules that exert deleterious effects on DNA involving solely singlet oxygen as reactive species. Most of PHYinduced lesions are single strand breaks and, to a lesser extent, base oxidized sites, which are recognized by Nth, Nfo and Fpg enzymes. High pressure liquid chromatography coupled to electrochemical detection revealed that PHY photosensitization did not induce 8-oxo7,8-dihydro-2'-deoxyguanosine (8-oxodGuo) at detectable levels. DNA repair after PHY photosensitization was also investigated. Plasmid DNA damaged by PHY photosensitization was used to transform a series of Saccharomyces cerevisiae DNA repair mutants. The results revealed that plasmid survival was greatly reduced in rad14 mutants, while the oggl mutation did not modify the plasmid survival when compared to that in the wild type. Furthermore, plasmid survival in the oggl radl4 double mutant was not different from that in the radl4 single mutant. The results reported here indicate that lethal lesions induced by PHY plus VL are repaired differently by prokaryotic and eukaryotic cells. Morever, nucleotide excision repair seems to play a major role in the recognition and repair of these lesions in Saccharomyces cerevisiae.

\section{Introduction}

Photosensitizers have been extensively used in DNA repair research due to their ability to induce oxidative damage (1-4). Recently, the relationship among oxidative stress, aging and some degenerative diseases has been demonstrated in humans (5-7). Therefore, photodynamic compounds may constitute an important tool that can be used
Key words

- Phycocyanin

- Saccharomyces cerevisiae - OGG1

- Nucleotide excision repair ..................... to mimic oxidative stress and to study the pathways involved in the recognition and repair of these lesions. Phycocyanin (PHY) has been reported to exert a variety of biological effects, including photodynamic action (PDA) (8-10), anti-inflammatory activity in animal models $(11,12)$ and protection against hepatotoxins (13). PHY has also been used as a molecular marker for electrophoretic techniques (14) and as a food additive 
$(15,16)$. Its structure is based on an openchain tetrapyrrolic chromophore covalently bound to an apoprotein, which possesses two chromophores attached to the alpha subunit and one to the beta subunit $(17,18)$. Indeed, the photosensitizing properties of PHY are linked to light activation, which seems to be related to the tetrapyrrolic chromophore light absorption, rather than to light absorption by the apoprotein $(8,10,19)$. On the other hand, the anti-inflammatory and scavenging effects of PHY are not related to light activation and may be due, in these cases, to an apoprotein protective action $(11,13)$. If PHY is considered to be a photosensitizer, it may exert its biological effect by two different pathways (type I and type II reactions), with the prevalence of one over the other being dependent on the chemical nature of the sensitizer and on the molecular oxygen content in the reaction (20). In the type I reaction, there is a direct electron transfer from the photosensitizer to the DNA, while in the type II reaction there is an energy transfer or electron transfer from the photosensitizer to molecular oxygen (20). Recently, we demonstrated that DNA damage induced by PHY plus visible light (VL) could be repaired in vitro by Fpg protein and that it depended on the $u v r A$ gene of E. coli in vivo. Furthermore, the photodynamic action of PHY could be inhibited by the addition of atoxic concentrations of sodium azide, indicating the production of singlet oxygen (10). The Fpg, as well as Nth, Nfo and Xth proteins belong to the base excision repair (BER) and the UvrABC complex belongs to the nucleotide excision repair (NER), the most effective pathways that bacterial cells possess to counteract oxidative damage in DNA $(21,22)$. BER and NER are also present in yeast and in human cells (22). Saccharomyces cerevisiae possesses a functional homolog of the bacterial $\mathrm{fpg}$ gene, the $O G G 1$ gene, which, like $f p g$, is responsible for the recognition and repair of 8-oxo-7,8-dihydro-2'-deoxyguanosine (8-
oxodGuo) and 2,6-diamino-4-hydroxy-5-Nmethylformamidopyrimidine (FapyGua) (23).

In the present study we used purified DNA repair endonucleases to characterize the chemical profile of PHY-induced lesions in the presence of VL. The identification of DNA damage was based on the substrate specificity of the following DNA repair enzymes from E. coli: the Fpg and Nth proteins for photo-oxidized purines and pyrimidines, respectively, and the Nfo protein for regular and modified abasic sites or AP sites $(3,4$, $21,24)$. The production of 8 -oxodGuo was monitored in PHY and methylene blue (MB)photodamaged DNA using HPLC coupled to an electrochemical detector (HPLC-ECD). We have also investigated the repair of DNA lesions induced by the PHY and MB photosensitization using the YEplac181 plasmid DNA, which was treated with both photosensitizers in a cell-free system and then used to transform a series of $S$. cerevisiae DNA repair mutants. The yeast cells were also directly submitted to the photodynamic action of PHY and MB.

The results reported here demonstrate that PHY induces photooxidative damages in DNA that represent mostly single strand breaks followed, to a lesser extent, by base-oxidized sites. Moreover, only the NER system of Saccharomyces cerevisiae, but not the $O G G 1$ gene, was found to be involved in the repair of lethal lesions induced by PHY plus VL. Thus, oxidative damage induced by PHY is repaired in different manners in prokaryotic and eukaryotic organisms.

\section{Material and Methods}

\section{Chemicals}

Methylene blue was purchased from Sigma Chemical Co., St. Louis, MO, USA, and stock solutions $(200 \mu \mathrm{g} / \mathrm{ml})$ were made in PBS and kept at $4^{\circ} \mathrm{C}$. Phycocyanin was 
purified from Spirulina platensis as previously described (10). Salmon sperm DNA was purchased from Sigma, rehydrated in PBS and kept at $-80^{\circ} \mathrm{C}$. Proteinase $\mathrm{K}$ was purchased from Sigma.

\section{Yeast and bacterial strains}

Escherichia coli JM105 [supE endA $s b c \mathrm{~B} 15$ hsd R4 rpsL thi $\Delta$ (lac-proAB)/F' (traD36 lac ${ }^{\mathrm{q}} \Delta$ (lacZ) M15 proA $\left.^{+} \mathrm{B}^{+}\right)$] was from our laboratory stock in France. All Saccharomyces cerevisiae strains used in the present study and derived from FF18733 [MATo, his7, leu2, lys 1, ura3, trp1] were from Dr. Francis Fabre, Institut Curie, Paris. CD138 [ogg1 ::TRP1], BP10 [rad14::URA3] and BP20 [ogg1::TRP1 rad14::URA3] were from our stock laboratory in France $(25,26)$.

\section{Cell growth}

Escherichia coli JM105 was grown in LB broth at $37^{\circ} \mathrm{C}$ with shaking. The medium was supplemented with ampicillin $(100 \mu \mathrm{g} /$ $\mathrm{ml}$ ) when cells were hosting plasmid YEplac181. Yeast strains were grown in YPD medium ( $1 \%$ yeast extract, $1 \%$ bacto peptone and $2 \%$ glucose) or YNBD minimal medium $(0.7 \%$ yeast nitrogen base without amino acids and containing $2 \%$ glucose) at $30^{\circ} \mathrm{C}$ with shaking (27). YNBD medium was supplemented with histidine $(100 \mu \mathrm{g} / \mathrm{ml})$, leucine $(100 \mu \mathrm{g} / \mathrm{ml})$, lysine $(40 \mu \mathrm{g} / \mathrm{ml})$, uracil $(20 \mu \mathrm{g} / \mathrm{ml})$ or tryptophan $(20 \mu \mathrm{g} / \mathrm{ml})$ according to the auxotrophic requirements of each yeast strain. Solid medium was prepared by the addition of $2 \%$ agar to yeast medium and of $1.5 \%$ to the bacterial medium.

\section{Plasmid and DNA repair endonucleases}

Plasmid YEplac181 [LEU2-2 $\left.\mu, \mathrm{Amp}^{\mathrm{R}}\right]$ (28) was prepared from transformed JM105 using the Qiagen midi-prep kit (Qiagen, Paris, France) and stored at $-20^{\circ} \mathrm{C}$ in TE buffer. The DNA repair endonucleases Fpg, Nth and Nfo were prepared from overproducing $E$. coli strains and purified to apparent homogeneity according to previously described methods and were from our laboratory stock (29-31).

\section{Photosensitization of yeast and plasmid DNA}

Yeast cells were grown in YPD medium and incubated for $24 \mathrm{~h}$ at $30^{\circ} \mathrm{C}$ with shaking. An aliquot was then taken and diluted in fresh YPD medium to obtain a $0.2 \mathrm{~A}_{650 \mathrm{~nm}}$. This culture was incubated at $30^{\circ} \mathrm{C}$ with shaking to reach a density of $10^{7}$ cells $/ \mathrm{ml}$. The cells $(10 \mathrm{ml})$ were washed twice with PBS and resuspended in PBS containing PHY $(500 \mu \mathrm{g} / \mathrm{ml})$. The cell suspension was incubated in the dark for $1 \mathrm{~h}$ at $30^{\circ} \mathrm{C}$ with shaking. Irradiation with VL was performed at room temperature in Petri dishes ( $3.0 \times 1.0$ $\mathrm{cm}$ ) containing $2.0 \mathrm{ml}$ of cell suspension as previously described (10). Plasmid YEplac181 $(25 \mu \mathrm{g} / \mathrm{ml})$ was diluted in PBS buffer and incubated in the presence of PHY $(500 \mu \mathrm{g} / \mathrm{ml})$ or MB $(2 \mu \mathrm{g} / \mathrm{ml})$. Each mixture $(200 \mu \mathrm{l})$ was placed in a 96 -well microtiter plate and irradiated at $0^{\circ} \mathrm{C}$. Irradiation with VL was performed using a GE PAR 38 "Cool beam" $220 \mathrm{~V} / 150 \mathrm{~W}$ lamp as previously described (10). Fluence was measured with a YSI-Kettering model 65A radiometer (Yellow Spring Instruments, Yellow Spring, $\mathrm{OH}$, USA). After PDA treatment, the cell suspension was diluted and plated onto YPD and scored after 48 -h incubation at $30^{\circ} \mathrm{C}$. MBtreated DNA was ethanol precipitated, washed with $70 \%$ ethanol and resuspended in $50 \mu \mathrm{l}$ of $\mathrm{BE}_{16}$ buffer (26). Phycocyanintreated DNA was incubated with proteinase $\mathrm{K}\left(5 \mu \mathrm{g} / \mathrm{ml}\right.$ in $\mathrm{BE}_{16}$ buffer $)$ for $30 \mathrm{~min}$ at $37^{\circ} \mathrm{C}$ and extracted with phenol/chloroform before ethanol precipitation.

\section{Q uantification of DNA strand breaks and endonuclease-sensitive sites}

The standard reaction mixture $(20 \mu \mathrm{l}$ fi- 
nal volume) contained $0.15 \mu \mathrm{g}$ of plasmid YEplac181 DNA, either untreated or treated with PHY or MB PDA, and 10 ng of Fpg, Nth or Nfo proteins (4). The reactions were carried out at $37^{\circ} \mathrm{C}$ for $15 \mathrm{~min}$ and stopped by the addition of $3 \mu 110 \%$ SDS. The reaction mixtures were then submitted to $0.8 \%$ gel agarose electrophoresis. The fraction of supercoiled and open circular DNA was determined after ethidium bromide staining and analysis using the Image Store System V.5 and quantified with the NIH Image Program. The average number of strand breaks per circle was calculated assuming a Poisson distribution of the lesions (24).

\section{Preparation of competent cells and transfor- mation}

Transformation of the Saccharomyces cerevisiae strains with YEplac181 plasmid DNA was performed by the lithium acetate method (28). Yeast transformants were plated onto YNBD-agar without leucine and scored after 72 -h incubation at $30^{\circ} \mathrm{C}$.

\section{Detection of 8-oxodGuo in DNA treated with PHY or MB plus visible light}

The presence of 8-oxodGuo was determined by HPLC-ECD. The analyses were performed using a Waters chromatographic system coupled to an electrochemical detector (Waters, model 460). A C18 $\mu$ Bondapack column equilibrated with methanol/water $(5: 95, \mathrm{v} / \mathrm{v})$ containing $50 \mathrm{mM}$ sodium citrate, $\mathrm{pH} 5.0$ (BSC solution), was used. The electrochemical detector was calibrated at $700 \mathrm{mV}$ with $100 \mu \mathrm{l}$ of an 8-oxodGuo standard solution $(0.1 \mu \mathrm{M}$ in BSC). All the analyses were performed under isochratic conditions at $1 \mathrm{ml} / \mathrm{min}$. Salmon sperm DNA (500 $\mu \mathrm{g} / \mathrm{ml})$ was treated with PHY $(1 \mathrm{mg} / \mathrm{ml})$ or MB $(5 \mu \mathrm{g} / \mathrm{ml})$ plus VL as described for plasmid DNA in Material and Methods. The samples were ethanol precipitated and resuspended in $\mathrm{BE}_{15}$ (10). A 5- $\mu$ l aliquot of each sample was used to react with Fpg protein $(50 \mu \mathrm{g} / \mathrm{ml})$ for $1 \mathrm{~h}$ at $37^{\circ} \mathrm{C}$ in $\mathrm{BE}_{15}$ (final volume $10 \mu \mathrm{l}$ ). The reactions were stopped by the addition of $90 \mu \mathrm{l}$ ice cold BSC. The samples were then injected into the HPLC-ECD apparatus. The number of 8oxodGuo $/ 10^{5}$ DNA bases was calculated by the method of Karahalil et al. (32).

\section{Results}

\section{Enzymatic recognition of DNA lesions induced by PHY}

In order to determine the chemical nature of DNA lesions induced by PHY plus VL we used a set of DNA repair endonucleases purified from Escherichia coli. Enzymatic recognition of DNA lesions constitutes a strategy that has been widely used for DNA damage characterization. In this test, supercoiled double-stranded plasmid DNA (YEplac181) was treated with PHY or with MB plus VL. After photosensitization, plasmid DNA was incubated with one of the following repair endonucleases from E. coli: Fpg, Nth and Nfo proteins. These enzymes are able to nick DNA at the phosphodiester backbone in a specific manner and induce relaxation of the supercoiled DNA. Single strand breaks corresponded to DNA strand breaks induced by the PDA of PHY or MB without post-incubation in the presence of repair endonucleases. Figure 1 shows SSB and enzyme-sensitive sites in DNA treated with PHY or MB plus VL. The most frequent DNA modifications induced in DNA after PHY photosensitization are single strand breaks, followed by Fpg- and Nth-sensitive sites, which are likely to be damaged purines and pyrimidines, respectively (Figure 1). Nfosensitive sites were less abundant, indicating that base loss sites are produced to a lesser extent after PHY photosensitization. In contrast to PHY plus VL, MB phototreatment induces a large excess of Fpg-sensitive sites and few single strand breaks (Figure 1). 


\section{Detection of 8-oxodGuo in DNA treated with PHY and MB plus VL using HPLC-ECD}

In early studies, it was reported that PHY photosensitization may involve the production of reactive oxygen species. The addition of sodium azide protected bacteria against the lethal effects of PHY plus VL (10). Furthermore, the Fpg protein, which recognizes 8-oxodGuo, was able to nick DNA in vitro after PHY plus VL treatment (10). Moreover, 8-oxodGuo is a coding lesion that increases the incidence of $\mathrm{GC} \rightarrow \mathrm{TA}$ transversions in bacterial and yeast mutants defective in Fpg and Ogg1 functions, respectively $(25,33)$. These results led us to monitor the formation of 8-oxodGuo in DNA after PHY photosensitization. Using HPLC-ECD, the production of 8-oxodGuo was measured in DNA treated with MB or PHY in the presence of increasing VL doses (Figure 2). In the presence of $\mathrm{MB}$, increasing $\mathrm{VL}$ induced 8 -oxodGuo in DNA, reaching a plateau at $720 \mathrm{~kJ} / \mathrm{m}^{2}$ (1-h light exposure), which may be due to an equilibrium in 8-oxodGuo degradation/formation in DNA (34). On the other hand, after PHY photosensitization, no significant amount of 8-oxodGuo was detected in DNA, indicating that 8-oxodGuo is not produced in DNA or is being produced at a very low rate (Figure 2).

\section{Survival of Saccharomyces cerevisiae cells and of YEplac181 plasmid DNA treated with PHY plus VL}

None of the yeast strains tested was sensitive to phycocyanin PDA. The FF18733 (wild type), CD138 (oggl) BP10 (rad14) and BP20 (ogg1 rad14) strains were submitted to PHY plus VL treatment under different conditions: increasing dye concentration, enhanced incubation temperature, increased incubation periods in the dark (over $2 \mathrm{~h}$ ) and increasing visible light doses. However, even in these conditions, survival of PHY plus VL-treated cells remained the same

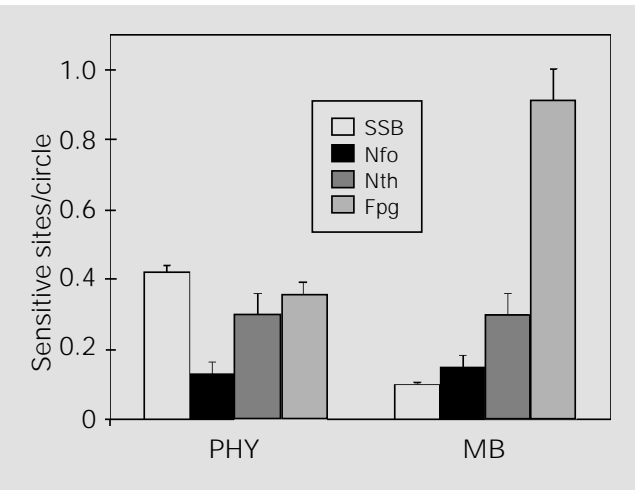

as that of the control cells, without PHY (data not shown). Therefore, we decided to sensitize plasmid DNA and measure its survival after transformation in the $S$. cerevisiae strains. Figure 3 shows the survival of PHY photodamaged plasmid YEplac181 after transformation into different $S$. cerevisiae DNA repair mutants. Survival of the PHY photodamaged YEplac181 in ogg1 single mutant was not significantly different from that found in the wild type strain. On the other hand, survival of YEplac181 after PHY photosensitization was greatly reduced in rad14 mutants. The survival of PHY photodamaged YEplac181 in the ogg1 rad14 double mutant was not different from that in the rad14 single mutant. Taken together, these results indicate that the oggl mutation does not modify plasmid survival. Therefore, the rad14 mutation, which inactivates NER in $S$. cerevisiae, seems to play a major role in the elimination of lethal lesions induced by phycocyanin PDA.

\section{Survival of Saccharomyces cerevisiae cells and of YEplac181 plasmid DNA treated with methylene blue plus visible light}

Survival of Saccharomyces cerevisiae was measured after sensitization with MB. Although all strains proved to be sensitive to MB PDA, there were no significant differences in lethality between the wild type strain (FF18733) and the DNA repair mutants (data not shown). Therefore, YEplac181 plasmid
Figure 1 - Formation of single strand breaks (SSB) or enzymesensitive sites (ESS) in DNA treated with phycocyanin (PHY) or methylene blue (MB) plus visible light. YEplac181 plasmid DNA was either treated with PHY $(500 \mu \mathrm{g} / \mathrm{ml}$ plus visible light: 2 min exposure $\left.\left(25 \mathrm{~kJ} / \mathrm{m}^{2}\right)\right)$ or MB $(1 \mu \mathrm{g} / \mathrm{ml}$ plus visible light: 12.5 -s exposure $\left(2.5 \mathrm{~kJ} / \mathrm{m}^{2}\right)$ ). Treated or untreated DNA was incubated with $10 \mathrm{ng}$ of the purified E. coli endonucleases: Fpg, $\mathrm{Nth}$ or Nfo. The average number of nicks per molecule was determined using $0.8 \%$ agarose gel electrophoresis as described in Material and Methods. SSB were induced in DNA treated with $\mathrm{MB}$ and $\mathrm{PHY}$ plus visible light without incubation in the presence of repair endonucleases. SSB in DNA treated with $\mathrm{PHY}$ or MB plus visible light were subtracted from ESS. In all figures, the results obtained correspond to three independent experiments. 
Figure 2 - Detection of 8-oxodGuo in DNA treated with phycocyanin (PHY) or methylene blue (MB) plus visible light. Salmon sperm DNA was first treated with PHY or MB plus visible light and then with Fpg protein $(50 \mu \mathrm{g} /$ $\mathrm{ml}$ ) for $1 \mathrm{~h}$ at $37^{\circ} \mathrm{C}$ as described in Material and Methods. Each final mixture $(100 \mu \mathrm{l})$ was injected into the HPLC-ECD system. The number of 8 -oxodGuo/ $10^{5}$ DNA bases was calculated and the limit of sensitivity was six 8-oxodGuo per $10^{5}$ DNA bases (32). Total exposure time was $1.5 \mathrm{~h}\left(1,080 \mathrm{~kJ} / \mathrm{m}^{2}\right)$

Figure 3 - Survival of YEplac181 plasmid DNA treated with PHY plus visible light when transformed into wild type (WT) and excision repair mutants of Saccharomyces cerevisiae. YEplac181 DNA was incubated with $500 \mu \mathrm{g} / \mathrm{ml} \mathrm{PHY} \mathrm{in} \mathrm{PBS} \mathrm{buffer} \mathrm{and} \mathrm{irradiated} \mathrm{with} \mathrm{differ-}$ ent doses of visible light. Untreated and treated DNA were used to transform the following competent yeast hosts: FF18733 (wild type), CD138 (ogg1), BP10 (rad14) and BP20 (ogg1 rad14). Total exposure time was $2.0 \mathrm{~h}$ $\left(1,440 \mathrm{~kJ} / \mathrm{m}^{2}\right)$.

Figure 4 - Survival of YEplac181 treated with MB plus visible light when transformed into wild type (WT) and excision repair mutants of Saccharomyces cerevisiae. YEplac181 DNA was incubated with $2 \mu \mathrm{g} / \mathrm{ml} \mathrm{MB}$ in PBS buffer and irradiated with visible light. Untreated and treated DNA was used to transform the following competent yeast hosts: FF18733 (wild type), CD138 (ogg1) BP10 (rad14) and BP20 (ogg1 rad14). Total exposure time was $16 \mathrm{~min}\left(240 \mathrm{~kJ} / \mathrm{m}^{2}\right)$.
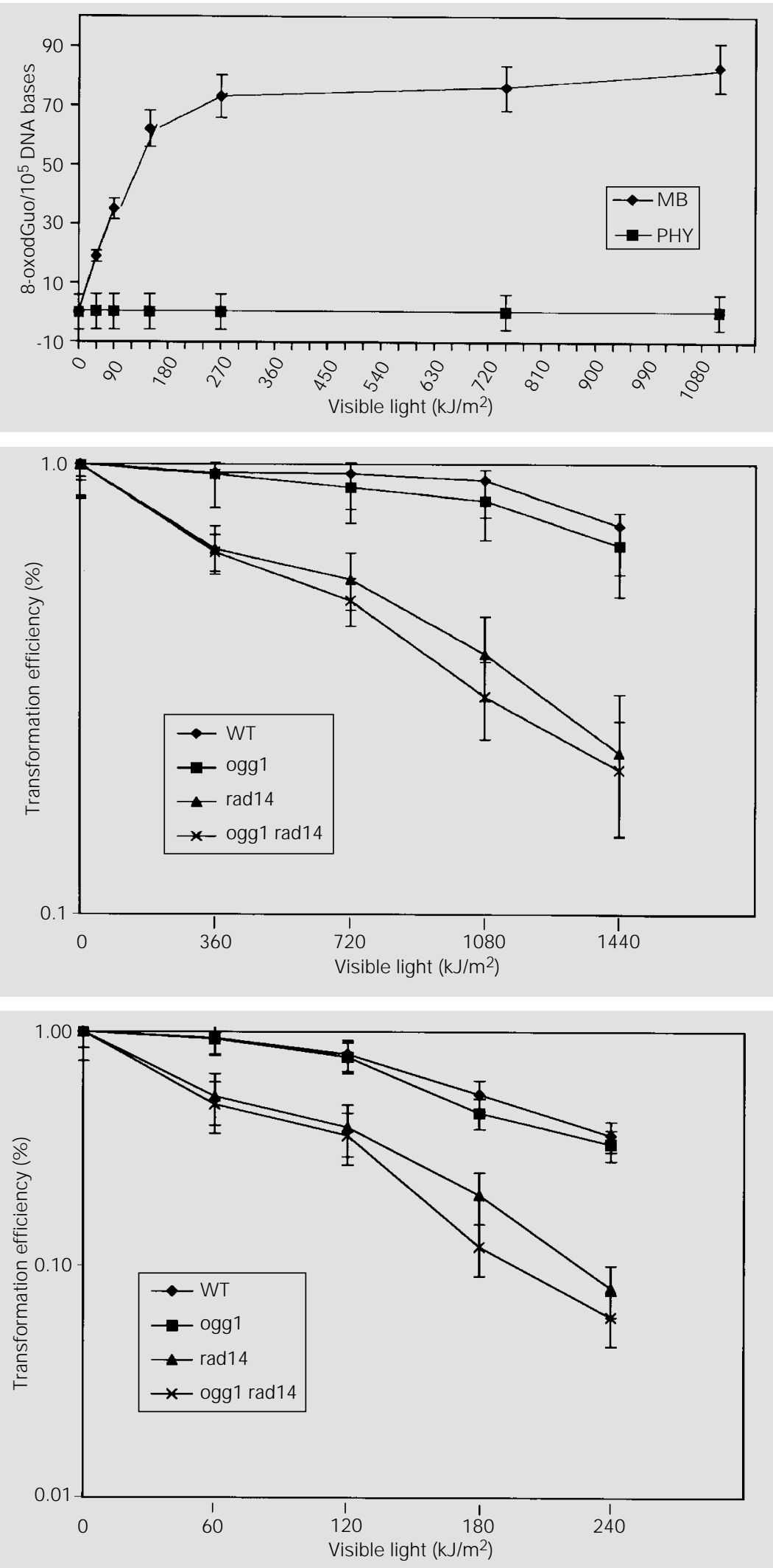
DNA was sensitized to determine the role of BER and NER in the repair of MB plus VLinduced lethal lesions in yeast. Figure 4 shows survival of YEplac181 plasmid DNA treated with MB plus VL after transformation in $S$. cerevisiae wild type and DNA repair mutants. Similarly to YEplac181 survival with PHY plus VL, when plasmid DNA was sensitized with $\mathrm{MB}$ and transformed into $S$. cerevisiae, its survival was reduced only in the rad14 mutants. The ogg1 mutation had no effect in reducing plasmid survival compared to the wild type strain.

\section{Discussion}

In the present study, we analyzed the damage profile and repair of DNA lesions induced by the photodynamic action of phycocyanin in vitro and in a cellular system. The damage profile of DNA exposed to PHY plus VL was determined using a set of DNA repair endonucleases purified from $E$. coli. The DNA damage profile of PHY-induced lesions was different from that of MB-induced lesions. While MB plus VL induces a large excess of Fpg-sensitive sites, PHY photosensitization mostly induced single strand breaks (Figure 1). The major difference between these two profiles is in the number of Fpg-sensitive sites generated by the treatments. The excess of Fpg-sensitive sites generated by MB photosensitization can be explained by the production of 8-oxodGuo, which was not detected after PHY plus VL treatment. In fact, the profile of DNA damage induced by phycocyanin was quite similar to that induced by ionizing radiation or by hydrogen peroxide in the presence of transition metals $(3,35)$, but was different from that induced by molecules which involve solely singlet oxygen as the major species responsible for the DNA modifications, such as heat decomposition of 3,3'-(1,4 naphthylidene)-dipropionate endoperoxide, $\mathrm{NDPO}_{2}$ (3). Since PHY photosensitization did not induce 8-oxodGuo in DNA (Figure 2), we conclude that singlet oxygen is not being produced or is immediately quenched by the apoprotein itself. This reasoning is valid when PHY anti-inflammatory properties are associated with oxygen free radical scavenging (12). Since the tetrapyrrolic chromophores are found in the apoprotein core (19), the production and diffusion of singlet oxygen may be hindered by the shielding and quenching effects of the apoprotein. Therefore, PHY photosensitization may occur via a type I reaction. The Fpg-sensitive sites found in DNA after PHY photosensitization may be due to the induction of open imidazole ring purines, such as 2,6-diamino-4-hydroxy-5$\mathrm{N}$-methylformamidopyrimidine (MeFapyGua) or 4,6-diamino-5 formamidopyrimidine (FapyAde), which can be found in DNA after reaction with $\bullet \mathrm{OH}$ radical (34). In addition, PHY-photosensitized DNA also presents Nth- and Nfo-sensitive sites, which may constitute oxidized pyrimidine-derived lesions and AP sites, respectively.

Phycocyanin was incapable of sensitizing Saccharomyces cerevisiae probably due to a cell wall barrier that prevents phycocyanin from penetrating and exerting its effects. We have shown that phycocyanin could interact with Gram-positive, but not Gramnegative, bacteria, which could justify its effectiveness in sensitizing Staphylococcus epidermidis, but its failure in sensitizing $E s$ cherichia coli (10). This same problem arose when MB was used to sensitize DNA repair mutants of $E$. coli, a fact that led researchers to sensitize plasmid DNA in cell-free systems to study DNA repair (36). For the reasons considered above, YEplac181 plasmid DNA was photosensitized in vitro and used to transform a series of $S$. cerevisiae DNA repair mutants. Considering the two binomes fpg/OGG1 and $u v r A / R A D 14$, we can propose that the plasmid survival obtained in $S$. cerevisiae after PHY phototreatment is different from that obtained in bacterial hosts (10). Indeed, after PHY plus VL treatment, plasmid survival was only diminished in the 
fpg/uvrA double mutant of E. coli, while its survival in the single mutants was similar to that in the wild type strain (10). Similar results were also obtained when plasmid DNA was treated with MB plus VL and used to transform these same E. coli repair mutants (36). On the other hand, in S. cerevisiae, plasmid survival after PHY photosensitization was greatly reduced only in rad14 mutants (Figure 3). Plasmid survival in the double mutant ogg1 rad14 was the same as that in the single mutant rad14, indicating that an ogg1 mutation against a rad14 background had no effect on plasmid survival. Moreover, plasmid survival in the oggl single mutant was similar to that in the wild type strain, showing that the $O G G 1$ gene itself does not play a role in the repair of the lethal lesions induced by PHY plus VL. The same results were obtained for plasmid DNA treated with MB plus VL and used to transform the $S$. cerevisiae strains (Figure 4). In E. coli, the Fpg protein and NER system are able to recognize PHY- or MB-induced lesions independently and to perform DNA repair. Plasmid survival is only diminished in the absence of both activities, indicating that Fpg and NER recognize the same DNA lesions. In S. cerevisiae, only the NER system is able to recognize PHY- or MB-induced lesions since plasmid survival is not altered by inactivation of the $O G G 1$ gene. Apparently, the difference between bacterial and yeast repair of $\mathrm{PHY}$ - and MB-induced lesions may reside in the Fpg/Ogg1 substrate specificity, in a possible BER backup conferred by the Ntg1 protein and, finally, in the NER backup of $S$. cerevisiae $(32,37)$. If PHY photosensitization does not induce 8-oxodGuo in DNA, the Fpg-sensi- tive sites found after DNA treatment may be due to Me-FapyGua or FapyAde lesions. Both are lethal lesions that can be well recognized by Fpg protein, but only Me-FapyGua is recognized by $\operatorname{Ogg} 1(21,32)$. In addition, the Ogg1 protein has a marked preference for AP sites opposite cytosine, while the Fpg protein cleaves AP sites opposite any one of the four DNA bases (32). Although MB produces high levels of 8-oxodGuo, this may not be important in terms of plasmid lethality since it is a pre-mutagenic rather than a lethal lesion $(25,38)$. Besides, if MeFapyGua, FapyAde, and even 8-oxodGuo lesions were not repaired by the Ogg1 protein, they may be recognized by the Ntg1 protein in $S$. cerevisiae $(37,39)$. Since $E$. coli does not possess a backup system for oxidized purine lesions, the simultaneous inactivation of the $f p g / u v r A$ will result in plasmid lethality. In $S$. cerevisiae, since Ntg1 may serve as a backup for Ogg1, plasmid lethality is only observed in the rad14 mutants. Consequently, one may suppose that the NER system of $S$. cerevisiae differs from that of $E$. coli in terms of lesion recognition and repair, since the former is responsible for the repair of PHY and MB lethal lesions that are not recognized by Ogg1 or Ntg1.

In conclusion, the results reported here demonstrate that $\mathrm{PHY}$ photosensitization induces mainly single strand breaks in DNA and, to a lesser extent, base oxidized sites. Furthermore, oxidative damage induced by PHY plus VL is repaired differently in Escherichia coli and in Saccharomyces cerevisiae, a fact that may be due to a BER backup conferred by the Ntg1 protein and to a NER backup of Saccharomyces cerevisiae.

\section{References}

1. Epe B, Hegler J \& Wild D (1989). Singlet oxygen as ultimately reactive species in Salmonella typhimurium damage induced by methylene blue/visible light. Carcinogenesis, 10: 2019-2024.
2. Menezes S, Capella MAM \& Caldas LR (1990). Photodynamic action of methylene blue: repair and mutation in Escherichia coli. J ournal of Photochemistry and Photobiology. B, Biology, 5: 505-517.
3. Epe B, Pflaum M \& Boiteux S (1993). DNA damage induced by photosensitizers in a cellular and cell-free systems. Mutation Research, 299: 135-145.

4. Boiteux S, Yeung AT \& Sage E (1993). 
Enzymatic recognition and biological effects of DNA damage induced by 3carbethoxypsoralen plus UVA. Mutation Research, 294: 43-50.

5. Breimer LH (1990). Molecular mechanisms of oxygen radical carcinogenesis and mutagenesis, the role of base damage. Molecular Carcinogenesis, 3: 188197.

6. Feig DI, Reid TM \& Loeb LA (1994). Reactive oxygen species in tumorigenesis. Cancer Research, 54 (Suppl): 1890-1894.

7. Demple B \& Harrison L (1994). Repair of oxidative damage to DNA: enzymology and biology. Annual Review of Biochemistry, 63: 915-948.

8. Morcos NC, Berns M \& Henry WL (1988). Phycocyanin laser activation, cytotoxic effects, uptake and human aterioesclerotic plaque. Lasers in Surgery and Medicine, 8: 10-17.

9. Morcos NC, Zaldivar F, Lo Hsueh M \& Henry WL (1991). Bovine coronary artery endothelium: Culture, characterization, angiogenesis and sensitivity to laser photodynamic treatment modalities. J ournal of Clinical and Laboratory Immunology, 34: 99-106.

10. Pádula M, Boiteux S, Felzenszwalb I \& Menezes S (1996). Photodynamic action of phycocyanin: damage and repair. J ournal of Photochemistry and Photobiology. B, Biology, 32: 19-26.

11. Romay C, Armesto J, Remierz D, Gonzales R, Ledon N \& Garcia I (1998). Antioxidant and anti-inflammatory properties of C-phycocyanin from blue-green algae. Inflammation Research, 47: 36-41.

12. Romay C, Ledon N \& Gonzales R (1998). Further studies on anti-inflammatory activity of phycocyanin in some animal models of inflammation. Inflammation Research, 47: 334-348.

13. Vadiraja BB, Gaikwad NW \& Madyastha KM (1998). Hepatoprotective effect of Cphycocyanin: protection for tetrachloride and R-(+)-pulegone-mediated hepatotoxicity in rats. Biochemical and Biophysical Research Communications, 249: 428-431.

14. Araoz R, Lebert M \& Hader DP (1998). Electrophoretic applications of phycobiliproteins. Electrophoresis, 19: 215-219.

15. Yoshida A \& Takagaki Y (1995). Detection of food additives by enzyme immunoassay. Nippon Rinsho, 53: 2316-2321.

16. Yoshida A, Takagaki $Y \&$ Nishimune $T$ (1996). Enzyme immunoassay for phycocyanin as the main component of spirulina color in foods. Bioscience, Biotechnology and Biochemistry, 60: 57-60.

17. Killilea SD, O'Carra P \& Murphy RF (1980).
Structures and apoprotein linkages of phycoerythrobilin and phycocianobilin. Biochemical J ournal, 187: 311-320.

18. Brown B \& Holroyd J A (1984). Biosynthesis of the chromophore of phycobiliproteins. Biochemical J ournal, 217: 265-272.

19. Berns DS \& MacColl R (1989). Phycocyanin in physical-chemical studies. Chemical Reviews, 89: 807-825.

20. Foote CS (1991). Definition of type I and type II photosensitized oxidation. Photochemistry and Photobiology, 54: 659.

21. Boiteux S (1993). Properties and biological functions of the Nth and Fpg proteins of Escherichia coli: two DNA glycosylases that repair oxidative damage in DNA. J ournal of Photochemistry and Photobiology. B, Biology, 19: 87-96.

22. Friedberg E, Walker GC \& Siede W (1995). DNA Repair and Mutagenesis. ASM Press, Washington, DC.

23. Auffret van der Kemp $P$, Thomas $D$, Barbey $\mathrm{R}$, de Oliveira $\mathrm{R} \&$ Boiteux $\mathrm{S}$ (1996). Cloning and expression in Escherichia coli of the OGG1 gene of Saccharomyces cerevisiae, which codes for a DNA glycosylase that excises 7,8-dihydro-8oxoguanine and 2,6-diamino-4-hydroxy-5$\mathrm{N}$-methylformamidopyrimidine. Proceedings of the National Academy of Sciences, USA, 93: 5197-5202.

24. Epe B, Herzl H, Adam W \& Saha-Möller CR (1993). Endonuclease sensitive DNA modifications induced by acetone and acetophenone as photosensitizers. Nucleic Acids Research, 21: 863-869.

25. Thomas $D, S$ cott $A D$, Barbey R, Pádula $M$ \& Boiteux S (1997). Inactivation of OGG1 increases the incidence of GC $\rightarrow$ TA transversions in Saccharomyces cerevisiae: evidence of endogenous oxidative damage to DNA in eukaryotic cells. Molecular and General Genetics, 254: 171178.

26. Pádula $M$, Averbeck $S$, Boiteux $S \&$ Averbeck D (1997). Enzymatic recognition and biological effects of photodynamic damage induced in DNA by 1.6-dioxapyrene plus UVA. J oumal of Photochemistry and Photobiology. B, Biology, 41: 6066.

27. Cherest H \& Surdin-Kerjan Y (1992). Genetic analysis of new mutations conferring cystein auxotrophy in Saccharomyces cerevisiae: updating of the sulphur metabolism pathway. Genetics, 130: 5158.

28. Gietz RD \& Sugino A (1988). New yeastEscherichia coli shuttle vectors constructed with in vitro mutagenized yeast genes lacking six-base pair restriction sites. Gene, 74: 527-534.

29. Cunningham RP, Saporito SM, Spitzer SG $\&$ Weiss B (1986). Endonuclease IV (nfo) mutant of Escherichia coli. J ournal of Bacteriology, 168: 1120-1127.

30. Asahara H, Wistort PM, BankJ F, Bakerian RH \& Cunningham RP (1989). Purification and characterization of Escherichia coli endonuclease III from the cloned nth gene. Biochemistry, 28: 4444-4449.

31. Boiteux S, O'Connor TR, Lederer F, Gouyette A \& Laval J (1990). Homogeneous Escherichia coli Fpg protein. A DNA glycosylase which excises imidazole ringopened purines and nicks DNA at apurinic/ apirimidinic sites. Journal of Biological Chemistry, 265: 3916-3922.

32. Karahalil B, Girard PM, Boiteux $S \&$ Dizdaroglu M (1998). Substrate specificity of the Ogg1 protein of Saccharomyces cerevisiae: excision of guanine lesions produced in DNA by ionizing radiation- or hydrogen peroxide/metal ion-generated free radicals. Nucleic Acids Research, 26: 1228-1233.

33. Boiteux S \& Huisman O (1989). Isolation of a formamidopyrimidine DNA glycosylase (fpg) mutant of Escherichia coli K12. Molecular and General Genetics, 215: 300-305.

34. Cadet J , Berger M, Douki T \& Ravanat J L (1997). Oxidative damage to DNA: formation, measurement and biological significance. Reviews of Physiology, Biochemistry and Pharmacology, 131: 3-87.

35. Epe B (1995). DNA damage profiles induced by oxidizing agents. Reviews of Physiology, Biochemistry and Pharmacology, 127: 223-249.

36. Czeczot H, Tudek B, Lambert B, Laval J \& Boiteux S (1991). Escherichia coli Fpg protein and UvrABC endonuclease repair DNA damages induced by methylene blue plus visible light in vitro and in vivo. J ournal of Bacteriology, 173: 3419-3424.

37. Sentürker $S$, Auffret van der Kemp P, You HJ , Doetsch PW, Dizdaroglu M \& Boiteux $S$ (1998). Substrate specificities of the $\mathrm{Ntg} 1$ and Ntg2 protein of Saccharomyces cerevisiae for oxidized DNA bases are not identical. Nucleic Acids Research, 26: 5270-5276.

38. Grollman AP \& Moriya M (1993). Mutagenesis by 8-oxoguanine: an enemy within. Trends in Genetics, 9: 246-249.

39. Bruner SD, Nash HM , Lane WS \& Verdine GL (1998). Repair of oxidatively damaged guanine in Saccharomyces cerevisiae by an alternative pathway. Current Biology, 26: 393-403. 